The main purposes of this study were to test music majors' abilities to harmonize notated melodies and recorded melodies with chord symbols, and to perform harmonic accompaniments to recorded melodies; measure the effectiveness of a harmonic audiation and performance training program; and measure the predictive power of eight independent variables on harmonic audiation and performance skills. Six subtesis were administered in a pre-post design to 45 instrumental music education majors, 22 of whom received training via the taped training program in the interim. The results suggested that the training program was effective in improving subjects' abilities to harmonize simple melodic patterns; that melodic echo-playing ability was highly correlated with and predictive of harmonic audiation and performance; that keyboard study had particularly weak relationships with harmonic audiation and performance; and that subjects were much better able to represent harmony implied by notated melodies than to represent or perform harmony implied by taped melodies.

Jere T. Humphreys, West Virginia University

\title{
Measurement, Prediction, and Training of Harmonic Audiation and Performance Skills
}

Improvised accompanying by music teachers has long been advocated as a means for improving music teaching. Both the Music Educators National Conference (Klotman, 1972) and the College Band Directors National Association (Spicer, 1977) have suggested that music teachers should be able to employ accompanying instruments as teaching tools.

The research literature on accompanied versus unaccompanied melodies indicates that elementary-age subjects' perceptions of pitches and intonation are improved when melodies are accompanied. Petzold $(1966,1969)$ found significantly greater accuracy in elementary children's melody singing when both stimulus models and children's re-

This article is based on the author's doctoral dissertation, "An Investivation of an Experimental Harmonic Audiation Skills Testing and Training Program for Instrumental Music Education Majors," University of Michigan, 1984. For reprints, contact Jere T. Humphreys, College of Creative Arts, West Virginia University, Morgantown, West
Virginia 26506. 
sponses were accompanied by simple three-chord progressions than when melodies were unaccompanied. In preliminary trials of materials for the Elementary Music Achievement Tests, Colwell (1965) reported that accompanied melodies were "distinctly easier" for pupils to perceive than unaccompanied melodies. Results of studies involving college-age students are mixed (Geringer, 1976; Ritchie, 1960).

Unfortunately, most music teacher training programs do little to help music majors develop accompanying skills that would benefit their future students (Case, 1977; Hunter, 1973). Further, at least some music teachers believe that accompanying instruments could not or should not be used in music classes. A survey of junior high school band directors in the state of Michigan revealed that many think of accompanying instruments only in terms of their playing a part, not as teaching tools to be used whether or not a written part exists (Humphreys, 1980). There appear to be no research studies that measure, predict, or train the ability of music majors to audiate harmony implied by melodies or to perform appropriate accompaniments when visual stimuli are not present.

The main purposes of this study were to: (a) test music majors' abilities to harmonize notated melodies and recorded melodies with chord symbols, and to perform harmonic accompaniments to recorded melodies; (b) measure the effectiveness of a harmonic audiation and performance training program; and (c) measure the power of eight independent variables to predict various harmonic audiation-performance abilities.

\section{INSTRUMENTATION}

Six unpublished subtests (Froseth, 1982d) used in this study were designed to measure undergraduates' abilities to: (a) harmonize notated melodic patterns using chord symbols (notational presentation, notational response), (b) harmonize recorded melodic patterns using chord symbols (auditory presentation, notational response), and (c) perform harmonic accompaniments to recorded melodic patterns (auditory presentation, performance response). There was one major and one minor mode subtest for each of the three presentation-response modes. Melodic patterns and harmonic progressions were similar to those commonly found in American folk music, and were identical on all three types of subtests. ${ }^{1}$ Only $\mathrm{C}$ major and A minor were used to minimize technical performance problems. Harmony was limited to the three primary chords in each mode: C, F, and G7 in major, and A minor, D minor, and $E_{7}$ in minor. There were 67 implied chords on each of the two notational-notational and two auditory-notational subtests. Each melodic pattern was repeated on the auditory-performance subtests for a total of 134 implied chords on each subtest. A woodblock indicated when chords were to be played on the auditory-performance subtests.

The training program (Froseth, 1982a) was composed of similar

\footnotetext{
Melodic patterns used in this study are available from the author.
} 
musical materials and was designed to improve the ability to audiate and perform implied harmonic accompaniments. Recorded training exercises were in a listen-play-listen-play format in which the melody was nized the melody), played with an ap layed alone again (subjects harmolistened), and played again with appropriate accompaniment (subjects nized along with the recorded accom accompaniment (subjects harmoMusical with the recorded accompaniment).

Musical examples on the training program and taped subtests were Fender Rhodes professional recording artists on an acoustic piano or drum set. Each example was or acoustic guitar, a bass guitar, and a establish the mode and te was preceded by a short introduction to style. major-instrument echo-playingles used in this study were: (a) a test of musical discrimination ability (Frolity (Froseth, 1982b), (b) a test of ory grades, (d) freshman writen theory 1982c), (c) freshman aural theaverages, (f) years of keyboard study, (h) class levels (sophomore through, (g) years of guitar experience, and The echo-playing test was cough graduate)

terns performed on an alphaSynposed of 100 four-beat melodic patarranged in nine sequences of intauri digital synthesizer. Patterns were each sequence the subject was told the difficulty. At the beginning of she listened to each pattern and then starting note, after which he or

with a rhythmic beat in the background.

which consisted of three short musical composed of 32 exercises, each of each exercise differed from each orher in melody, rhythm, harmony, tempo, pitch one or more ways including timbre, and rhythmic and expressive nuance ments was used. Subjects were to deterine. A wide variety of instruidentical and which were differe to determine which examples were

\section{PROCEDURE}

Following pilot testing of the materials, independent variable data were collected in the fall of 1982 from an intact instrumental methods laboratory class of 45 instrumental music education majors at West 19 females, and 1 graduate sophomores. Subjects' major instruments were 21 , 21 juniors, and 13 5 percussion, 4 strings, and 3 keyboard.

The musical discrimination andoard.

collectively in class and individually ouplaying tests $\cdots$ re administered subject played his or her major instrutside of class, respectively. Each two judges scored the test independenty on the echo-playing test, and variable data were gathered from questy. The remaining independent

Next, notational-notational and questionnaires and student records. ministered in class, and auditory-performance subtests were completed 
individually with two independent judges. Subjects chose to play the piano, guitar, or autoharp on the auditory-performance subtests.

Subjects were then randomly divided into control $(n=23)$ and experimental groups $(n=22)$. Control group subjects remained in class while the experimental group was divided into three groups that left the room one at a ime for training. Each subject chose to play the piano, guitar, or autoharp. The eight weekly training sessions, each lasting approximately $35 \mathrm{~min}$, were monitored by the investigator's assistant. During the final two weeks of training the most proficient subjects were exempted so that less proficient subjects could participate in longer training sessions. At the conclusion of the training program the six harmonic skills subtests were administered to all 45 subjects as a posttest. Subjects who missed portions of the training program were required to make up the missed portions. Mortality for the entire experiment was zero.

\section{RESULTS}

Reliability coefficients (split-half with Spearman-Brown correction) ranged from .45 to .88 for the six harmonic skills subtests (see Table 1), indicating substantial reliability at least for research purposes (Guilford \& Fruchter, 1978). Echo-playing and musical discrimination test reliabilities were .98 and .64 , respectively. Notational-notational subtests had substantially higher means and lower reliability coefficients than other subtests. This finding suggests that these subtests were too simple for subjects in this study, resulting in an inordinately large number of items with low or no variance. Auditory-performance subtest coefficients were somewhat higher than those for other subtests, probably as a result of greater test length. Interjudge reliability coefficients for the auditoryperformance and echo-playing measures ranged from .96 to .99 .

Pretest means were much higher on the notational-notational subtests than on either of the other types (see Table 1). Mean scores on auditoryperformance subtests must be halved for this comparison because these subtests were twice as long as the other subtests.

Results of $t$-test comparisons of pretest scores on the six harmonic skills subtests were that no pair of group means was close to meeting a .05 level of significance (see Table 1). The null hypothesis was not rejected in each case. A further search for pretest differences was made by applying a $t$-test to each individual item (chord) between groups. Of 536 items on the six subtests, only 13 were different at the .05 level, and none at the .01 level of significance. Such a small proportion of significantly different items could have occurred by chance.

Results of $t$-tests applied to mean gain scores displayed in Table 1 indicate that the training program was highly effective in training subjects to complete tasks on both auditory-performance subtests $(t=$ $-3.31 ; t=-3.04)$. Between group differences on the auditory-notational mean gain scores are noteworthy $(t=-1.74 ; t=-1.81)$, although they did not reach a .05 level of significance. The training program apparently had little effect upon notational-notational subtest scores $(t=-1.48 ; t=$ $-0.59)$. 
Table 1

Reliability Coefficients and Comparison of Experimental and Control Group Mean Pretest and Gain Scores on Harmonic Skills Battery

\begin{tabular}{|c|c|c|c|c|c|c|c|c|c|c|c|c|}
\hline \multirow[b]{2}{*}{ Subtest $^{\mathrm{a}}$} & \multicolumn{3}{|c|}{ Pretest } & \multicolumn{2}{|c|}{ Pretest } & \multirow[b]{2}{*}{$p$} & \multirow[b]{2}{*}{$M^{\mathrm{c}}$} & \multicolumn{3}{|c|}{ Posttest } & \multicolumn{2}{|l|}{ Gain } \\
\hline & Group $^{b}$ & $M^{c}$ & $r$ & difference & $t$ & & & $r$ & Gain d & difference & $t$ & $p$ \\
\hline Not-not major & $\begin{array}{l}\mathrm{C} \\
\mathrm{E}\end{array}$ & $\begin{array}{l}61.74 \\
60.09\end{array}$ & .88 & 1.65 & .87 & 7.3903 & $\begin{array}{l}62.57 \\
63.05\end{array}$ & .49 & $\begin{array}{r}.83 \\
2.96\end{array}$ & 2.13 & -1.48 & .1450 \\
\hline Not-not minor & $\begin{array}{l}\mathrm{C} \\
\mathrm{E}\end{array}$ & $\begin{array}{l}61.39 \\
59.55\end{array}$ & & 1.84 & .75 & 5.4613 & $\begin{array}{l}63.13 \\
62.59\end{array}$ & .45 & $\begin{array}{l}1.74 \\
3.04\end{array}$ & 1.30 & -0.59 & .5587 \\
\hline Aud-not major & $\begin{array}{l}\mathrm{C} \\
\mathrm{E}\end{array}$ & $\begin{array}{l}45.30 \\
49.14\end{array}$ & .59 & 3.84 & -1.59 & .1194 & $\begin{array}{l}49.91 \\
57.50\end{array}$ & .77 & $\begin{array}{l}4.61 \\
8.36\end{array}$ & 3.75 & -1.74 & .0891 \\
\hline Aud-not minor & E & $\begin{array}{l}48.22 \\
48.82\end{array}$ & .86 & .60 & -0.19 & .8522 & $\begin{array}{l}51.87 \\
57.59\end{array}$ & .85 & $\begin{array}{l}3.65 \\
8.77\end{array}$ & 5.12 & -1.81 & .0774 \\
\hline Aud-not major & $\begin{array}{l}\mathrm{C} \\
\mathrm{E}\end{array}$ & $\begin{array}{l}93.11 \\
92.91\end{array}$ & .77 & .20 & .07 & .9475 & $\begin{array}{r}99.87 \\
110.21\end{array}$ & .84 & $\begin{array}{r}6.76 \\
17.32\end{array}$ & 10.56 & -3.31 & .0030 \\
\hline Aud-not minor & $\begin{array}{l}\mathrm{C} \\
\mathrm{E}\end{array}$ & $\begin{array}{l}96.04 \\
96.89\end{array}$ & .84 & .85 & -0.19 & .8527 & $\begin{array}{l}101.22 \\
112.09\end{array}$ & .77 & $\begin{array}{r}5.18 \\
15.20\end{array}$ & 10.02 & -3.04 & .0048 \\
\hline
\end{tabular}

${ }^{a}$ Not $=$ notational; Aud $\approx$ auditory.

${ }^{b} \mathrm{C}=$ control group, $n=23 ; E=$ experimental group, $n=22$.

'Maximum score on auditory-performance subtests $=134$; maximum score on other subtests $=67$.

Correlation coefficients for the six harmonic skills subtests on the pretest administration indicate that the subtests were moderately to highly intercorrelated (.62 to .90 ) within each major-minor pair. Auditory-notational and auditory-performance subtests had moderately high coefficients (.62 to .79), implying strong relationships between the auditory-performance skills measured. Notational-notational subtests were intercorrelated least strongly with other subtests (.04 to .45).

Correlation coefficients for the eight independent variables show that echo-playing correlated moderately with musical discrimination (.46) and aural theory (.64), and musical discrimination with aural theory (.38). Intercorrelations among aural and written theory grades, gradepoint average, and class level ranged from .12 to .68 .

Zero-order correlations across control and experimental groups indicate that echo-playing and auditory-performance subtests were relatively highly correlated $(.75, .64)$, while coefficients between echo-playing and notational-notational subtests were relatively low $(.32, .35)$. Neither keyboard study nor guitar experience correlated significantly with any of the six harmonic skills subtests even though 41 of the 45 subjects in this study performed both auditory-performance subtests on the piano or guitar. This finding coupled with moderate to strong relationships between the performance subtests and aural measures such as echoplaying suggest that skills measured by the performance subtests were primarily aural rather than psychomotor in nature.

The eight independent variables served as predictor variables in the multiple regression analyses. Criterion variables were major and minor 
Trable 2

Multiple Regression Analysis of Major Mode Auditory-Performance Subtest Gain Scores

\begin{tabular}{|c|c|c|c|c|c|c|c|c|}
\hline \multirow[b]{2}{*}{ Step } & \multicolumn{4}{|c|}{$\begin{array}{c}\text { Control group } \\
(n=23) \\
\end{array}$} & \multicolumn{4}{|c|}{$\begin{array}{l}\text { Experimental group } \\
(n=22)\end{array}$} \\
\hline & Variable & $R^{2}$ & $F$ & $p$ & Variable & $R^{2}$ & $F$ & $p$ \\
\hline 1 & ATG & .10 & 2.26 & .1473 & WTG & .19 & 4.55 & .0455 \\
\hline 2 & MDS & .20 & 2.45 & .1120 & MDS & .26 & 3.37 & .0558 \\
\hline 3 & GYE & .27 & 2.36 & .1040 & ATG & .39 & 3.78 & .0289 \\
\hline 4 & KYS & .31 & 2.01 & .1356 & EPS & .51 & 4.46 & .0120 \\
\hline 5 & WTG & .31 & 1.55 & .2280 & CLS & .55 & 3.85 & .0175 \\
\hline 6 & GPA & .31 & 1.22 & .3455 & GPA & .56 & 3.12 & .0344 \\
\hline 7 & EPS & .32 & 1.00 & .4711 & KYS & .58 & 2.76 & .0505 \\
\hline 8 & CLS & .32 & .82 & .6007 & GYE & .63 & 2.78 & .0490 \\
\hline
\end{tabular}

EPS = echo-playing scores; $\mathrm{MDS}=$ musical discrimination scores; $\mathrm{ATG}=$ aural theory grades; WTG $=$ written theory grades; GPA $=$ grade-point averages; KYS $=$ keyboard years of study; GYE = guitar years of experience; CLS = class levels.

mode auditory-performance subtest pretest and gain scores. Separate regression equations were used for the experimental and control groups. Since the nature of this research was exploratory, the stepwise routine was altered to include all variables in each model instead of setting criteria for entrance to and removal from the models (Neter \& Wasserman, 1974).

Echo-playing test scores predicted large proportions $(.55, .55, .78)$ of variance in pretest scores in three of the four models (both groups on the major mode auditory-performance subtest, and the control group on the minor mode subtest). In the fourth model (experimental group on the minor mode subtest), in which echo-playing entered the model at the second step, it raised $R^{2}$ by a substantial amount (.08). These findings are in keeping with zero-order correlations reported earlier.

Echo-playing predicted relatively large proportions of variance in experimental group gain scores as well, accounting for approximately $12 \%$ and $15 \%$ of the variance on the major and minor subtests, respectively (see Tables 2 and 3). In general, echo-playing was a strong predictor of variance in experimental group gain scores and in pretest scores for both groups, followed by aural and written theory grades, musical discrimination test scores, and, to a lesser extent, guitar experience. Class levels, gradepoint averages, and keyboard study made very small contributions to the regression models.

\section{DISCUSSION}

The training program used in this study appears to have been effective in training instrumental music education majors to audiate and perform harmonic accompaniments implied by taped melodies. This finding demonstrates that students can be taught to audiate implied harmony. 
Table 3

Multiple Regression Analysis of Minor Mode Auditory-Performance Subtest Gain Scores

\begin{tabular}{|c|c|c|c|c|c|c|c|c|}
\hline \multirow[b]{2}{*}{ Step } & \multicolumn{4}{|c|}{$\begin{array}{l}\text { Control group } \\
(n=23) \\
\end{array}$} & \multicolumn{4}{|c|}{$\begin{array}{c}\text { Experimental group } \\
(n=22)\end{array}$} \\
\hline & Variable & $R^{2}$ & $F$ & $p$ & Variable & $R^{2}$ & $F$ & $p$ \\
\hline 1 & ATG & .11 & 2.65 & .1183 & EPS & .15 & 3.53 & .0749 \\
\hline 2 & MDS & .20 & 2.52 & .1052 & ATG & .31 & 4.30 & .0288 \\
\hline 3 & GYE & .29 & 2.64 & .0794 & WTG & .42 & 4.29 & .0190 \\
\hline 4 & EPS & .36 & 2.48 & .0804 & GPA & .63 & 7.11 & .0015 \\
\hline 5 & KYS & .38 & 2.10 & .1160 & MDS & .67 & 6.51 & .0018 \\
\hline 6 & CLS & .39 & 1.71 & .1835 & CLS & .70 & 5.82 & .0027 \\
\hline 7 & GPA & .39 & 1.38 & .2846 & GYE & .70 & 4.75 & .0064 \\
\hline 8 & WTG & .39 & 1.13 & .4022 & KYS & .71 & 3.93 & .0143 \\
\hline
\end{tabular}

Note. See Table 2 for label descriptions.

Subjects in this study were much better able to represent harmony implied by notated melodies than to represent or perform harmony implied by taped melodies. This finding suggests that subjects had received superior prior training in visually oriented notation, or that the aural tasks were inherently more difficult, or both. It appears that assumptions frequently made by teachers about the ready transfer of knowledge and skills between notational and auditory modes may be unwarranted.

On the other hand, the strong relationships between notating and performing harmony implied by recorded melodies suggest that training in one task would probably help in learning the other. The implication is that aural theory classes, by including more training in notating implied harmony rather than performed harmony (commonly called dictation), might aid students in learning to perform implied harmony as well. Further, strong relationships between melodic echoplaying and harmonic audiation and performance indicate that training in echo-playing might help students learn to perform implied harmonic accompaniments. More research is needed on these topics.

Weak relationships between harmonic audiation-performance skills and gradepoint averages and class levels suggest that work completed as a college music major, measured both qualitatively and quantitatively, may not be closely related to the types of aural musicianship measured in this study. Keyboard study, which has often been linked to aural musicianship (May \& Elliot, 1980; Ritchie, 1960), had particularly weak relationships with aural musicianship in this study. The apparent discrepancy was probably caused by the total absence of notation in much of the present sturdy.

Accompaniments in the music classroom would provide a heightened sense of harmony for singers and players of monophonic instruments as well as a more musical atmosphere for learning and enjoyment. Data from this study indicate that music majors could be trained to audiate and perform harmony implied by simple melodies. 
Replication studies should use larger samples, a longer training period, and individual rather than group training sessions. Studies of relationships among harmonic audiation and performance, echo-playing, and standard measures of musical aptitude are also suggested.

\section{REFERENCES}

Case, T. G. (1977). A comparison of expected and observed piano skills required The of public school music University of North Carolina at Greensboro.

doctoral dissertation, Universily of North Cant test manual: Experimental edition.

Colwell, R. J. (1965).

Chicago: Follett. gram.

Froseth, J. O. (1982b). Test of instrumental performance skills (TIPS) for teaching. Unpublished test.

Froseth, J. O. (1982c). Test of musical discrimination. Unpublished test.

Froseth, J. O. (1982d). Tests of harmonic audiation. Unpublished tests.

Geringer, J. M. (1976). Intonational performance and perception of accompa-

nied and unaccompanied ascending scalar patterns. Unpublished doctoral dissertation, Florida State University.

Guilford, J. P., \& Fruchter, B. (1978). Fundamental statistics in psychology and education (6th ed.) New York: McGraw-Hill.

Humphreys, J. T. (1980). Unpublished survey.

Hunter, R. J., Jr. (1973). The teaching of ten functional Coast four-year undergraduate music education majors at selected West Coast four of the colleges and universities. Unpublished doctoral dissertation, Universiy of the Pacific.

Klotman, R., Chairman. (1972). Teacher education in music: Final report. Washington, D.C.: Music Educators National Conference.

May, W. V., \& Elliott, C. A. (1980). Relationships among ensemble participation, private instruction, and aural skill development. Journal of Research in Music Education, 28, 155-161.

Neter, J. \& Wasserman, W. (1974). Applied linear statistical models: Regression, analysis of variance, and experimental designs. Homewood, IL: Richard D. Irwin.

Petzold, R. G. (1966). Development of auditory perception of musical sounds by children in the first six grades. Washington, D.C.: Department of Health, Education, and Welfare.

Petzold, R. G. (1969). Auditory perception by children. Journal of Research in Music Education, 17, 82-87. Ritchie, T. V. (1960). A study of the effects of Unpublished doctoral dissertation, perception of selected

(1977). The education of the band director: Second Spicer, R., Chairman. (1977). The educactors National Association research report-competencies. College Band Directors Nation committee report. Journal of Band Research, 13, 10-19.

December 3, 1985 